\title{
Transient Calculations of SPERT III Experiments
}

\author{
Alexander Aures ${ }^{1,2}$, Andreas Pautz ${ }^{2}$, and Winfried Zwermann ${ }^{1}$ \\ ${ }^{1}$ Gesellschaft für Anlagen- und Reaktorsicherheit (GRS) gGmbH \\ Boltzmannstr. 14, 85748 Garching, Germany \\ ${ }^{2}$ École polytechnique fédérale de Lausanne \\ 1015 Lausanne, Switzerland
}

alexander.aures@grs.de, andreas.pautz@epfl.ch,winfried.zwermann@grs.de

\begin{abstract}
Cold-startup and hot-standby reactivity accident tests conducted at the SPERT III E-core research reactor are analysed with the coupled neutron-kinetic/thermal-hydraulic code system DYN3D-ATHLET. Homogenised 2-group cross sections for DYN3D are thereby generated with the Monte Carlo neutron transport code Serpent 2 in combination with the ENDF/B-VII.1 cross section library. Results in terms of maximum power, energy release, and reactivity compensation are in good agreement with the experimental values. The time-dependent contributions to the reactivity feedback are investigated for both a cold-startup test and a hot-standby test. These findings prove the suitability of the combined application of the simulation codes to predict the reactor dynamic behaviour in the event of prompt-critical and super-prompt critical transients even for small reactor cores. Furthermore, static core characteristics of the SPERT III E-core reactor at cold-startup condition are analysed with using a static DYN3D model, a detailed Serpent reference model, and a simplified Serpent model consistent with the DYN3D model. The critical control rod position and the excess reactivities of both the control rods and the transient rod obtained with the Serpent reference model are consistent with the experimental values. For the same parameters, the DYN3D model is in good agreement with the Serpent simplified model.
\end{abstract}

KEYWORDS: SPERT III E-core, RIA analysis, Serpent, DYN3D-ATHLET, KMACS

\section{INTRODUCTION}

The SPERT III (Special Power Excursion Reactor Test III) E-core reactor was a small, $\mathrm{UO}_{2}$-fueled, pressurised water research reactor operated at the National Reactor Testing Station in Idaho, USA. In the 1960's, reactivity accident tests were performed under initial conditions similar to those of a commercial light water reactor in order to gather experimental power excursion data and investigate reactivity feedback effects. By rapid ejection of a centrally located transient rod (TR), reactivities ranging from $0.5 \$$ to $1.3 \$$ were inserted into the core. Tests at low initial power $(50 \mathrm{~W})$ were carried out at cold- and hot-startup conditions, and tests at high initial power ( $1 \mathrm{MW}$ or $20 \mathrm{MW}$ ) were performed at hot-standby and operating-power conditions [1,2]. The comprehensive experimental data of the SPERT III E-core program provides a good opportunity to assess the ability of reactor 
kinetic codes to predict the reactor dynamic behaviour in the event of a reactivity initiated accident (RIA). In the last couple of years, analyses of the static core tests as well as of the reactivity accident tests have already been performed at several research institutes for code validation [3-8].

In this study, we analyse a selection of SPERT III tests with the coupled neutron-kinetic/thermalhydraulic $(\mathrm{NK} / \mathrm{TH})$ code system DYN3D-ATHLET using homogenised 2-group cross sections generated with the Monte Carlo code Serpent 2. Serpent is furthermore used for the analysis of static core characteristics under the cold-startup condition. In the following, we briefly describe the applied analysis tools and the reactor models that are built on the basis of several technical reports $[1,2,9,10]$. Finally, we provide results of the static core characteristics and of the dynamic $\mathrm{NK} / \mathrm{TH}$ calculations of selected tests.

\section{TOOLS AND MODELS DESCRIPTION}

\subsection{Tools}

Serpent 2 developed by VTT in Finland is a continuous-energy Monte Carlo particle transport code which allows neutron and photon transport simulations in three-dimensional geometries [11]. Typical applications of Serpent are, for example, criticality and burnup calculations, the generation of homogenised few-group cross sections, and multi-physics simulations via coupling to thermalhydraulic codes or fuel performance codes. In this study, Serpent is applied with the continuousenergy cross section library ENDF/B-VII.1 [12].

DYN3D developed by HZDR in Germany is a reactor dynamics code for steady-state and transient analysis of light water reactors with square or hexagonal assembly geometries [13]. The thermal-hydraulic system code ATHLET has been developed by GRS in Germany for the analysis of operational and abnormal conditions in nuclear reactors [14]. Both codes are coupled internally to build the NK/TH code system DYN3D-ATHLET. Pre- and post-processing, data storage, and execution of this code system is done with the GRS core simulator KMACS [15].

\subsection{Serpent Full-Core Models at Cold-Startup}

The Serpent reference model consists of the active core and the following components confining the active core: a bottom and a top grid, a core skirt, four thermal shields and a vessel wall (Figs. 1 and 2). The active core has a lattice pitch of $7.62 \mathrm{~cm} \times 7.62 \mathrm{~cm}$, and it is composed of 60 fuel assemblies in total: 48 fuel assemblies ( UO2 5x5) with a $5 \times 5$ fuel rod lattice, four fuel assemblies (UO2 4x4) in the core centre with a $4 \times 4$ fuel rod lattice, and 8 movable control rods $(C R)$. Every control rod consists of an absorber section, a flux suppressor and a fuel follower section (Fig. 2). All fuel assemblies are encased by stainless steel cans. All fuel assembly types use the same fuel rod type and the same fuel rod pitch which is $1.486 \mathrm{~cm}$. The fuel pellet has an outer diameter of $1.067 \mathrm{~cm}$ and consists of $\mathrm{UO}_{2}$ with a mass density of $10.5 \mathrm{~g} / \mathrm{cm}^{3}$ and an ${ }^{235} \mathrm{U}$ enrichment of $4.8 \%$. The cladding is modelled with type SS348 stainless steel and has an inner diameter of $1.082 \mathrm{~cm}$ and an outer diameter of $1.184 \mathrm{~cm}$. Both ends of the fuel rods are equipped with stainless steel end plugs. The helium and the compression spring in the expansion space above the upper fuel pellet are modelled as a homogenised material mixture. The active length of the fuel rods is $97.282 \mathrm{~cm}$. The upper section of a $C R$ is a hollow, square box made from the neutron absorbing 


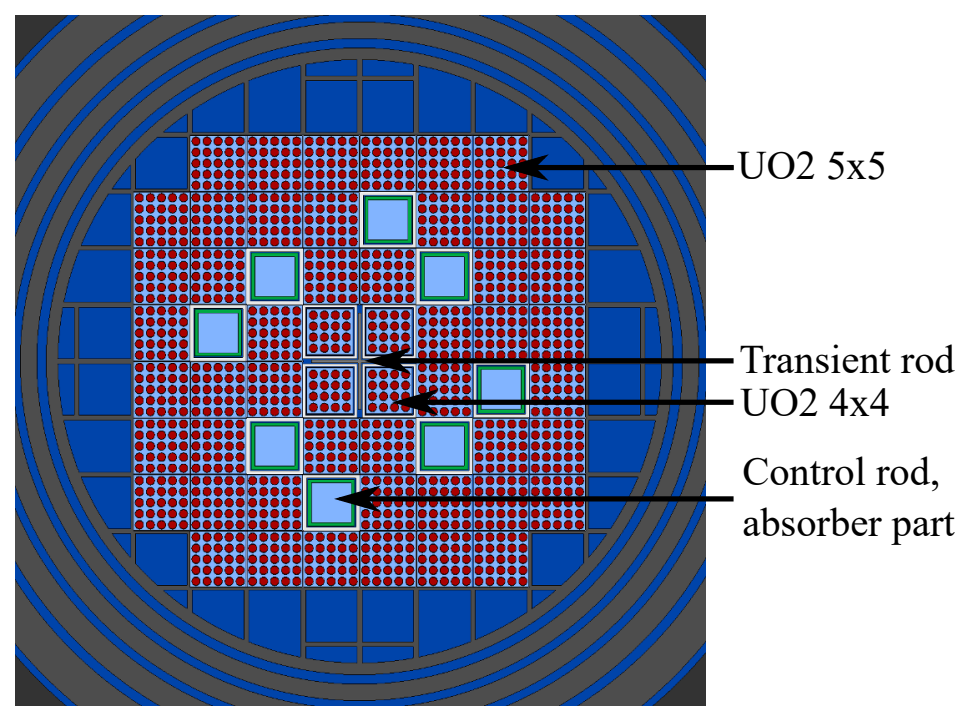

Figure 1: Horizontal view of the Serpent reference model of the SPERT III E-core with the fuel assembly types $U O 25 x 5$ and $U O 24 x 4$, the transient rod, and the control rods.

material $1.35 w t . \%{ }^{10} \mathrm{~B}$ in type SS304 stainless steel $\left(1.35 w t . \%{ }^{10} \mathrm{~B} / \mathrm{SS} 304\right)$. The lower section is a fuel follower with a $4 \times 4$ fuel rod lattice. The middle section contains a flux suppressor with two groups of six small absorber plates each. These plates also consist of $1.35 w t . \%{ }^{10} \mathrm{~B} / \mathrm{SS} 304$ and are arranged in a rectangular grid. The $C R s$ are surrounded by square guide tubes made from Zircaloy-2.

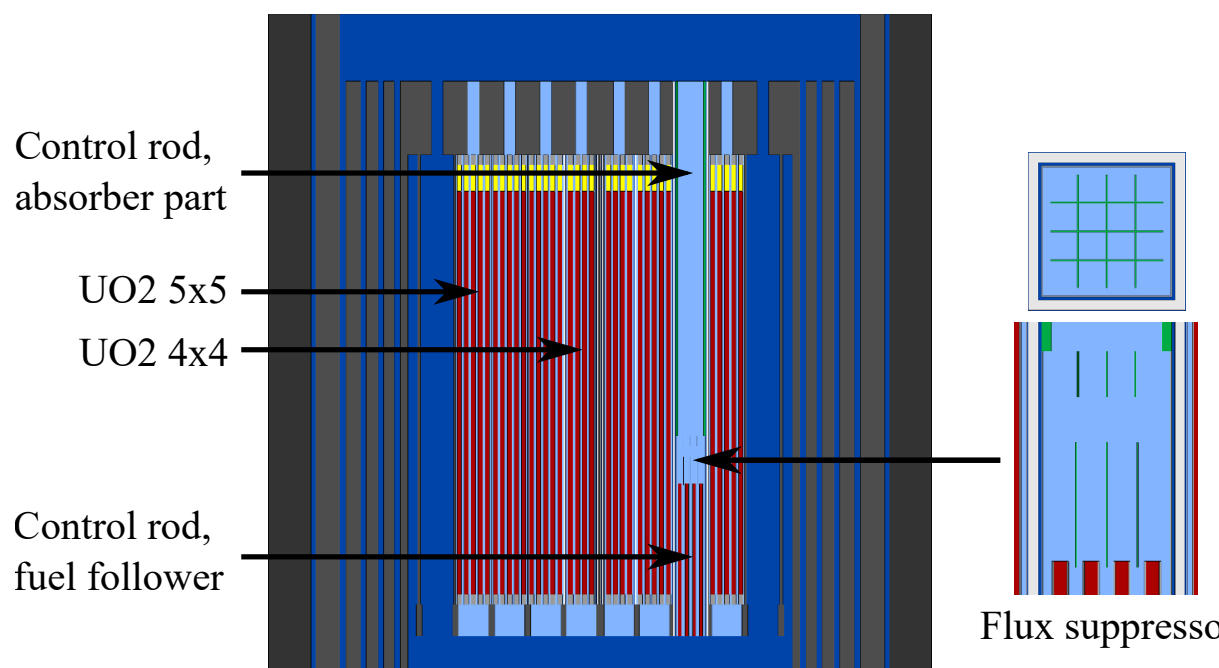

Figure 2: Left: Vertical view of the Serpent reference model of the SPERT III E-core with the fuel assembly types $U O 25 x 5$ and $U O 24 x 4$, and a control rod consisting of the three sections: absorber, flux suppressor, and fuel follower. Right: Horizontal view and vertical view of a flux suppressor. 
The cruciform transient rod (TR) used for initiating the transient has a thickness of $0.476 \mathrm{~cm}$ and a width of $13.018 \mathrm{~cm}$. It is located at the core centre and is axially divided into two sections. The lower section is $96.52 \mathrm{~cm}$ in length and is made of the neutron absorbing material $1.35 \mathrm{wt} . \%^{10} \mathrm{~B} /$ SS304. The upper section consists only of SS304. The TR is separated from the four central fuel assemblies by Zircaloy- 2 guide tubes surrounding each of the four fuel assemblies.

For better comparability with the DYN3D nodal diffusion model described below, an additional Serpent simplified model is built corresponding to the DYN3D model. The flux suppressors are neglected and every $C R$ consists only of an absorber section and a fuel follower section.

\subsection{DYN3D / DYN3D-ATHLET Models and Serpent Infinite Lattice Models}

The nodal model of the SPERT III E-core applied in the DYN3D calculations consists of 60 fuel assemblies, a top and a bottom reflector, and two rows of radial reflector assemblies. The flux suppressors in the control rods are not modelled. The radial discretisation is one node per assembly, while the active core region is axially discretised with 40 nodes, each with a height of $2.43205 \mathrm{~cm}$. The axial reflector nodes are $9.7282 \mathrm{~cm}$ in height. In the coupled DYN3D-ATHLET calculations, the ATHLET model simulates only the thermal-hydraulics of the core. Every fuel assembly is represented by a parallel independent fluid channel without cross flow. All radial reflector assemblies are combined in a bypass channel. The axial discretisation is the same as in the DYN3D model.

For the nodal calculations with DYN3D, we generated two libraries of 2-group cross sections: one for the cold-startup tests and one for the hot-standby tests. For this purpose, we built infinite lattice models of the various fuel assembly types as well as models of the various reflector types with Serpent. The libraries cover the following parameter ranges:

- Cold-Startup:

- System pressure: 1.013 bar

- Fuel temperature: $294 K-1300 K$

- Moderator density: $0.99803 \mathrm{~g} / \mathrm{cm}^{3}-0.95863 \mathrm{~g} / \mathrm{cm}^{3}$

- Hot-Standby:

- System pressure: 104.3 bar

- Fuel temperature: $500 K-1500 K$

- Moderator density: $0.791 \mathrm{~g} / \mathrm{cm}^{3}-0.683 \mathrm{~g} / \mathrm{cm}^{3}$

\section{Core Characteristics at Cold-Startup}

Table 1 lists static core characteristics for Cold-Startup (fuel temperature: $294 \mathrm{~K}$, moderator density: $0.99803 \mathrm{~g} / \mathrm{cm}^{3}$, system pressure: $1.013 \mathrm{bar}$ ) determined with the Serpent reference model, the Serpent simplified model, and the static DYN3D model, respectively. Additionally, experimental values are provided which are taken from [1]. The Serpent calculations are performed with 50.000 neutrons per cycle, 5.000 active cycles, and 150 inactive cycles.

The critical position of the $C R$ group of the Serpent reference model overestimates the measured value by about $1 \mathrm{~cm}$. In this case, the position describes the distance between the upper edge of 
Table 1: Static core characteristics of the SPERT III E-core for Cold-Startup from Serpent and DYN3D calculations compared with experimental data.

${ }^{1}$ Uncertainty results from statistical uncertainty of $\beta_{\text {eff }}$ from Serpent.

\begin{tabular}{|l|l|l|l|l|}
\hline & $\begin{array}{l}\text { Experiment } \\
{[1]}\end{array}$ & $\begin{array}{l}\text { Serpent } \\
\text { Reference }\end{array}$ & $\begin{array}{l}\text { Serpent } \\
\text { Simplified }\end{array}$ & DYN3D \\
\hline Critical $C R$ Position $[\mathrm{cm}]$ & 37.084 & 38.248 & 29.046 & 28.879 \\
\hline$C R$ Excess Reactivity [\$] & 14.12 & $14.12(6)$ & $14.03(6)$ & $13.58(5)^{1}$ \\
\hline$T R$ Excess Reactivity [\$] & 4.8 & $4.67(2)$ & $4.59(2)$ & $4.65(2)^{1}$ \\
\hline
\end{tabular}

the flux suppressors and the bottom of the active core. In case of the Serpent simplified model and the DYN3D model the flux suppressors are replaced by fuel. Therefore, the critical position, which is then the distance between the upper edge of the fuel follower section and the bottom of the active core, is necessarily much lower. The critical $C R$ position of the DYN3D calculation is in good agreement with the one of the Serpent simplified calculation. The calculation of the delayed neutron fraction based on the Serpent reference model yields $\beta_{\text {eff }}=743 \pm 3 \mathrm{pcm}$, while using the Serpent simplified model results in $\beta_{\text {eff }}=747 \pm 3 \mathrm{pcm}$ [16]. The latter is also used for the DYN3D model. With these delayed neutron fractions, excess reactivities of both the $C R$ group and the $T R$ are calculated. The excess reactivities of the $C R$ group obtained by both Serpent models match the experimental reactivity well. The DYN3D model underestimates the reactivity by about $400 \mathrm{pcm}$. All models underestimate the experimental $T R$ excess reactivities by between $97 \mathrm{pcm}$ and $163 \mathrm{pcm}$.
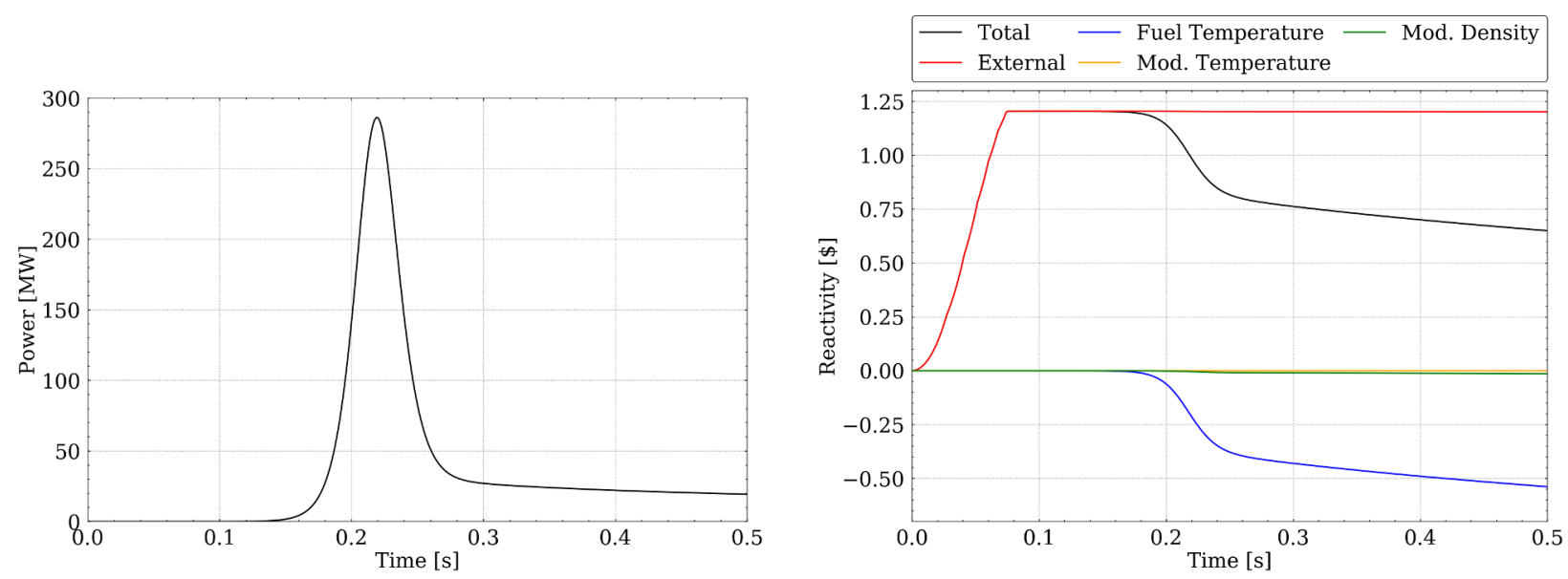

Figure 3: Power (left) and reactivity contributions (right) as a function of time of Test 43 for cold-startup condition calculated with DYN3D-ATHLET. 


\section{DYN3D-ATHLET Results of Reactivity Accident Tests}

For none of the tests the initial positions of both the $C R$ group and the $T R$ are available in the references, but only the initial reactivities. Thus, for every test, we calculated the initial positions of both rods such that the transient starts from criticality and that the withdrawal of the $T R$ leads to the reported initial reactivity. At transient start, the $T R$ is accelerated with $50.8 \mathrm{~m} / \mathrm{s}^{2}$. The coupled DYN3D-ATHLET calculations are performed with a time step size of $0.1 \mathrm{~ms}$.

The DYN3D-ATHLET calculation of Test 43 at cold-startup (CZP) condition results in a maximum power of $286.1 \mathrm{MW}$ at $0.22 \mathrm{~s}$ (Fig. 3, left). This is in good agreement with the measured maximum power of $280 \pm 17 \mathrm{MW}$ at $0.23 \pm 0.006 \mathrm{~s}$ (Table 2). The right-hand plot in Fig. 3 shows the development of the different reactivity contributions over time. The reactivity feedback results solely from the Doppler broadening caused by an increase of the fuel temperature. Moreover, results for the reactor period, the time of occurence of the maximum power, the energy release until the maximum power, and the reactivity compensation at the maximum power are in good agreement with the corresponding experimental values, see Table 2. Calculation results of both Test 48 and Test 49 at cold-startup condition are generally in good agreement with the experimental values (Table 2). For all cold-startup tests presented here, we observe that the maximum power occurs somewhat earlier than in the experiment.

Table 2: Reactivity accident test results for Cold-Startup (CZP) and Hot-Standby (HSB) calculated with DYN3D-ATHLET in comparison with experimental data. [10].

${ }^{1}$ Approximated value as reported in [10].

\begin{tabular}{|ll|l|l|l|l|l|l|}
\hline Test & & $\begin{array}{l}\text { Initial } \\
\text { reactivity } \\
{[\$]}\end{array}$ & $\begin{array}{l}\text { Maximum } \\
\text { power } \\
{[M W]}\end{array}$ & $\begin{array}{l}\text { Energy } \\
\text { release } \\
{[M J]}\end{array}$ & $\begin{array}{l}\text { Reactivity } \\
\text { compensation } \\
{[\$]}\end{array}$ & $\begin{array}{l}\text { Time at } \\
\text { max. power } \\
{[s]}\end{array}$ & $\begin{array}{l}\text { Reactor } \\
\text { period } \\
{[\mathrm{ms}]}\end{array}$ \\
\hline $\begin{array}{l}\text { Test } 43 \\
(\mathrm{CZP})\end{array}$ & Exp & $\begin{array}{l}1.21 \pm 0.05 \\
1.20\end{array}$ & $\begin{array}{l}280 \pm 17 \\
286.1\end{array}$ & $\begin{array}{l}6.0 \pm 1 \\
6.1\end{array}$ & $\begin{array}{l}0.22 \pm 0.02 \\
0.21\end{array}$ & $\begin{array}{l}0.23 \pm 0.006 \\
0.22\end{array}$ & $\begin{array}{l}10.0 \pm 0.3 \\
10.6\end{array}$ \\
\hline $\begin{array}{l}\text { Test } 48 \\
(\mathrm{CZP})\end{array}$ & Exp & $1.09 \pm 0.04$ & $63 \pm 9$ & $2.8 \pm 0.5$ & $0.11 \pm 0.01$ & $0.37 \pm 0.01$ & $21.1 \pm 0.4$ \\
& Calc & 1.09 & 68.8 & 3.1 & 0.11 & 0.35 & 22.0 \\
\hline $\begin{array}{l}\text { Test } 49 \\
(\mathrm{CZP})\end{array}$ & Exp & $1.00 \pm 0.04$ & $11 \pm 2$ & $2.1 \pm 0.4$ & $0.08 \pm 0.01$ & $0.97 \pm 0.04$ & $68.4 \pm 1.4$ \\
\hline $\begin{array}{l}\text { Test } 81 \\
\text { (HSB) }\end{array}$ & Exp & 1.01 & 12.3 & 2.3 & 0.08 & 0.85 & 66.4 \\
\hline
\end{tabular}

The calculated maximum power of $332 M W$ of Test 81 for hot-standby condition (Fig. 4, left) is in good agreement with the measured maximum power of $330 \pm 30 \mathrm{MW}$. The Doppler feedback is the major contributor to the reactivity feedback, while later on, the decrease of the moderator density is also an important contributor to the reactivity feedback (Fig. 4, right). At maximum power, the Doppler reactivity feedback is $0.14 \$$ and the reactivity feedback due to the moderator density change is $0.02 \$$. The energy release matches the experimental value and the time of occurence of the calculated maximum power is somewhat later (Table 2). A reactor period is not available because the reactor periods of the tests at high initial power were not stable due to significant reactivity feedback during and after the reactivity insertion [1]. 

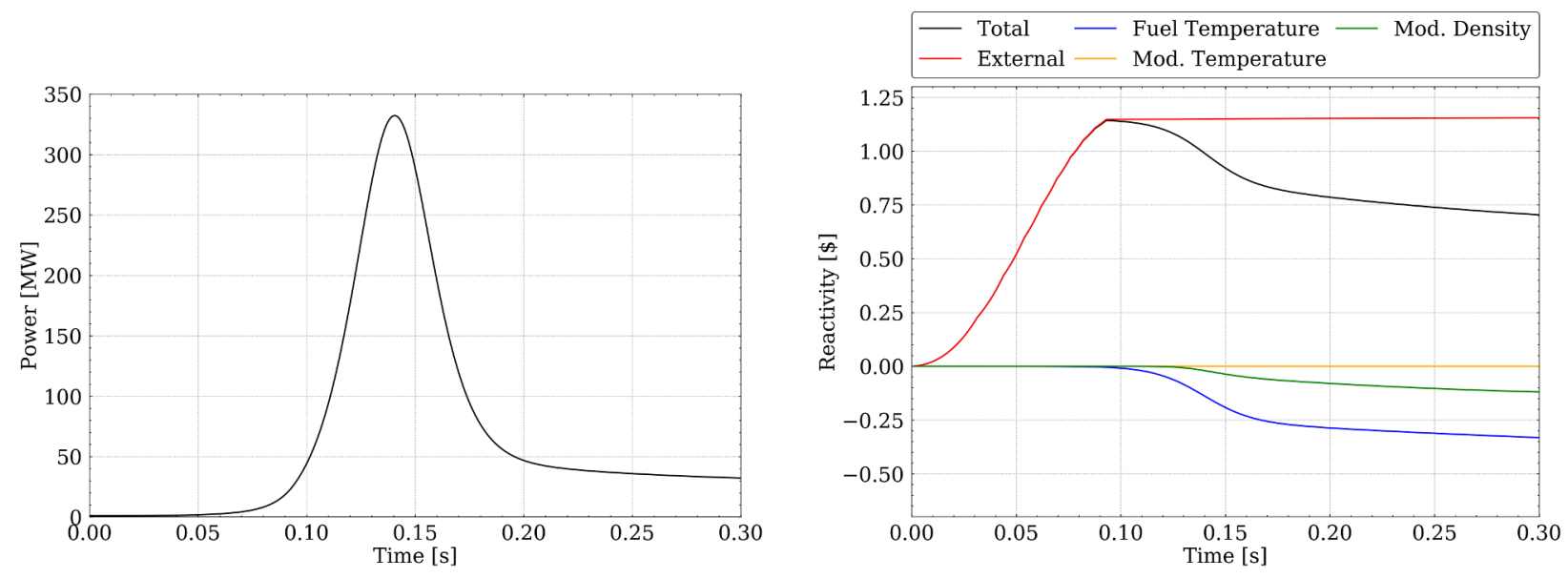

Figure 4: Power (left) and reactivity contributions (right) as a function of time of Test 81 for hot-standby condition calculated with DYN3D-ATHLET.

\section{CONCLUSIONS}

Static core characteristics as well as reactivity accident tests of the SPERT III E-core research reactor were analysed. The core characteristics for the cold-startup condition are analysed with the Monte Carlo code Serpent using a detailed reference model, in static calculations with the nodal diffusion code DYN3D, and with Serpent using a simplified model consistent with the static DYN3D model. Results from the Serpent reference model for the critical control rod position and the excess reactivities of both the eight control rods and the transient rod are in good agreement with the experimental values. The calculations with the Serpent simplified model and the DYN3D model match the experimental excess reactivities well. The cold-startup reactivity accident tests Test 43, Test 48, Test 49, and the hot-standby test Test 81 are calculated with the neutronkinetic/thermal-hydraulic code system DYN3D-ATHLET with homogenised 2-group cross sections generated from Serpent 2 infinite-lattice and reflector models. Results for the maximum power, the reactor period, the energy release until the time of occurence of the maximum power, and the reactivity compensation at maximum power are in very good agreement with the experimental values. This proves the suitability of DYN3D-ATHLET in combination with homogenised cross sections from Serpent for the analysis of prompt-critical and super-prompt critical reactivity accident tests even for small reactor cores. In future studies, analyses of hot-startup and operating power reactivity accident tests will be conducted. Moreover, the reactivity feedbacks will be studied in more detail.

\section{ACKNOWLEDGEMENTS}

This work was supported by the German Federal Ministry for Economic Affairs and Energy. 


\section{REFERENCES}

[1] R. K. McCardell et al., "Reactivity accident test results and analyses for the SPERT III Ecore - A small oxide-fueled, pressurized-water reactor," IDO-17281, U.S. Atomic Energy Commission, USA (1969).

[2] R. E. Heffner et al., "SPERT III Reactor Facility,” IDO-16721, U.S. Atomic Energy Commission, USA (1961).

[3] A. Dokhane et al., "Validation of PSI best estimate plus uncertainty methodology against SPERT-III reactivity initiated accident experiments," Annals of Nuclear Energy, 118, pp. 178-84 (2018).

[4] M. Knebel et al., "Validation of the Serpent 2-DYNSUB code sequence using the Special Power Excursion Reactor Test III (SPERT III)," Annals of Nuclear Energy, 91, pp. 79-91 (2016).

[5] A. Zoia et al., "Reactor physics analysis of the SPERT III E-core with Tripoli-4®," Annals of Nuclear Energy, 90, pp. 71-82 (2016).

[6] S. AOKI et al., "Analysis of the SPERT-III E-Core using ANCK Code with the Chord Weighting Method," Journal of Nuclear Science and Technology, 46, pp. 239-251 (2009).

[7] G. Grandi et al., "Qualification of CASMO5 / SIMULATE-3K against the SPERT-III E-core Cold Start-up Experiments," Proceedings of PHYSOR 2012 - Advances in Reactor Physics, Knoxville, USA, April 15-20, (2012).

[8] A. P. Olson, "Neutronics Calculations for SPERT-III, E-Core," ANL/GTRI/TM-13/10, Argonne National Laboratory, USA, May, (2012).

[9] J. Dugone, "SPERT III Reactor Facility: E-core Revision," IDO-17036, U.S. Atomic Energy Commission, USA (1965).

[10] INTERNATIONAL ATOMIC ENERGY AGENCY, "Research Reactor Benchmarking Database: Facility Specification and Experimental Data," Technical Reports Series No. 480, IAEA, Vienna, (2015).

[11] J. Leppaenen et al., "The Serpent Monte Carlo code: Status, development and applications in 2013," Annals of Nuclear Energy, 82, pp. 142-150 (2015).

[12] M.B. Chadwick, M. Herman, P. Obložinský, et al., "ENDF/B-VII.1 Nuclear Data for Science and Technology: Cross Sections, Covariances, Fission Product Yields and Decay Data", Nuclear Data Sheets, 112, pp. 2887 - 2996, 2011.

[13] U. Rohde et al., "The reactor dynamics code DYN3D - models, validation and applications," Annals of Nuclear Energy, 89, pp. 170-190 (2016).

[14] G. Lerchl et al., "ATHLET 3.1A User's Manual," GRS-P-1 / Vol. 1, Rev. 7, Gesellschaft für Anlagen- und Reaktorsicherheit (GRS) gGmbH, Germany, (2016).

[15] M. Zilly et al., "KMACS Validation Report," GRS-P-8 / Vol. 2, Rev. 0, Gesellschaft für Anlagen- und Reaktorsicherheit (GRS) gGmbH, Germany, (2018).

[16] J. Leppaenen et al., "Calculation of effective point kinetics parameters in the Serpent 2 Monte Carlo code," Annals of Nuclear Energy, 65, pp. 272-279 (2014). 